\title{
Control of a Hybrid Modular Multilevel Converter during Grid Voltage Unbalance
}

\author{
E. K. Amankwah, A. J. Watson, P. W. Wheeler, and J. C. Clare \\ Faculty of Engineering, The University of Nottingham, Nottingham, UK
}

Keywords: HVDC, modular multilevel, unbalance control, third harmonic injection control.

\begin{abstract}
The recently proposed parallel hybrid modular multilevel converter is considered to be a low loss, low component count converter with soft switching capability of the 'main' bridge. The converter has similar advantages to other emerging modular multilevel converter circuits being considered for HVDC power transmission. However, during ac network unbalance the individual 'chain-links' exchange unequal amounts of power with the grid which requires appropriate remedial action. This paper presents research into the performance of the converter and proposes a suitable control method that enables the converter to operate during grid voltage unbalance. The proposed control concept involves the use of asymmetric third harmonic voltage generation in the 'chain-links' of the converter to redistribute the power exchanged between the individual 'chain-links' and the grid. Mathematical analysis and simulation modelling with results are presented to support the work described.
\end{abstract}

\section{Introduction}

Modular multilevel voltage source converters (M2LC) are being developed for HVDC and FACTS applications [1-8]. These converters are expected to offer significant benefits over classical HVDC technology utilising Line Commutated Converters (LCCs) - lower harmonic content of the synthesised AC waveform, fast and independent control of active and reactive power, reduced filtering requirements, etc. As part of the efforts towards achieving an efficient modular converter topology for the emerging HVDC and FACTS market, a novel modular multilevel voltage source converter, shown in Figure 1, aimed at providing highly efficient modular converter technology was proposed. Research into the performance of the converter in a balanced network is presented in [7, 9-13]. The converter uses a cascade of half bridge cells to produce a full wave rectified multilevel waveform for each phase according to (1) during balanced network operations according to (2). At the zero crossing of the chainlink voltage, the 'main' H-bridge units are soft switched to "unfold" the chainlink voltage into AC at the network frequency.

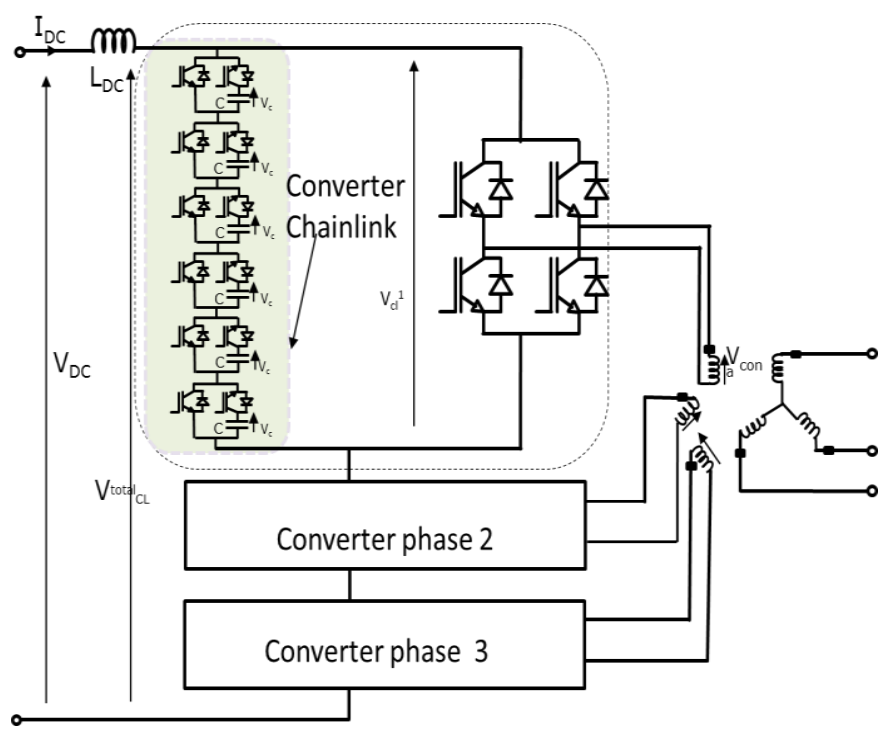

Figure 1: Converter Topology

$$
V_{c l}^{i}=\left|V \sin \left(\omega t-k \frac{2 \pi}{3}\right)\right|
$$

Where $k \epsilon\{0,1,2\}$ for $i \epsilon\{a, b, c\}$.

$$
V^{i}=V \sin \left(\omega t-k \frac{2 \pi}{3}\right)
$$

Under such operating conditions, it is has been shown that AC-DC power balance can be achieved without the chainlinks having to source or sink power [12]. Although, in practice an appropriate control action is required to achieve AC-DC power balance and ensure sustainable converter operation. 
In this paper, operation of a hybrid modular multilevel converter when connected to an unbalanced grid is investigated. Mathematical analysis and simulation models are used to describe the converter operating characteristics during unbalanced operation. It is shown that the converter chain-links exchange unequal amounts of power with the grid under unbalanced conditions.

A control algorithm that redistributes the power exchanged between the individual chain-links and the grid is proposed. This concept involves the use of asymmetric third harmonic voltage control in the chain-link voltages to avoid maloperation of the converter.

\section{Converter operation during grid voltage unbalance}

In the study, it is assumed that the neutral of the converter transformer is not grounded - and so there is no circulation of zero sequence components during unbalance. The unbalance factor $(\beta)$ represents the amplitude of the negative sequence voltage in the circuit [14] [15].

We consider a system where the grid voltage is composed of positive and negative sequence voltages during unbalance. It is considered that the converter is controlled to inject negative sequence voltage proportionate to that in the grid to avoid the circulation of negative sequence current. By so doing, it can be assumed that the current through the system is composed of positive sequence only.

The voltage at the converter terminal is therefore considered to contain a proportionate amount of negative sequence voltage as in (3)

$$
\begin{aligned}
V_{g}^{i}=V(\sin (\omega t & \left.-\frac{2 k \pi}{3}\right) \\
& \left.+\beta \sin \left(\omega t+\frac{2 k \pi}{3}\right)\right)
\end{aligned}
$$

which imposes the voltages described in (4) on the individual converter chain-links.

$$
\begin{aligned}
V_{c l}^{i}=V \mid \sin (\omega t & \left.-\frac{2 k \pi}{3}\right) \\
& +\beta \sin \left(\omega t+\frac{2 k \pi}{3}\right) \mid
\end{aligned}
$$

Here, it is assumed that the unbalance does not result in extra phase shift between the positive and negative sequence reference frames and therefore the zero crossing instants on phase ' $a$ ' are not affected. However, the zero crossing time instants of phases ' $b$ ' and ' $c$ ' are shifted according to the degree of unbalance in the system. The zero crossing time instants for the voltage on chainlink ' $b$ ' can be obtained as $t_{b}$ (5) and $t_{b}(6)$. Similar equations can be derived for the zero crossing time instants of the voltages on chainlink ' $c$ '.

$$
\begin{aligned}
& t_{b} \\
& =\frac{1}{\omega}\left(\frac{2 \pi}{3}\right. \\
& \left.+\arcsin \left(\frac{\sqrt{3}}{2} \frac{\beta}{\left(1+\beta^{2}+\beta\right)^{\frac{1}{2}}}\right)\right)
\end{aligned}
$$

$$
\begin{aligned}
& t_{b}{ }^{1} \\
& =\frac{1}{\omega}\left(-\frac{\pi}{3}\right. \\
& \left.+\arcsin \left(\frac{\sqrt{3}}{2} \frac{\beta}{\left(1+\beta^{2}+\beta\right)^{\frac{1}{2}}}\right)\right)
\end{aligned}
$$

The current through the system considering the case for active power exchange only can be presented in (7).

$$
I^{a b c}=I \sin \left(\omega t-\frac{2 k \pi}{3}\right)
$$

With an unbalance component of $\beta$ on the converter voltage, the peak voltage imposed on the chain-links can be obtained as (8) and (9).

$$
\begin{gathered}
{\widehat{V^{a}}}_{c l}=V(1+\beta) \\
\widehat{V}_{c l}^{b}=\widehat{V}_{c l}^{c}=V \sqrt{1+\beta^{2}+\beta}
\end{gathered}
$$

The unbalance on the AC side affects the DC component of the individual chain-links even when the negative sequence voltage introduced by the unbalance is synthesised by the chain-links to prevent the flow of negative sequence currents. The DC component of the imposed chain-link voltages can be derived as (10), (11), and (12) for chain-links 'a', 'b' and 'c'.

$$
\begin{gathered}
\bar{V}_{c l}^{a}=\frac{2}{\pi} V(1+\beta) \\
\bar{V}_{c l}^{b}=\frac{1}{\pi} V\left(-\cos \left(\omega t_{b}\right)+\sqrt{3} \sin \left(\omega t_{b}\right)\right. \\
-\beta\left(\cos \left(\omega t_{b}\right)\right. \\
\left.\left.+\sqrt{3} \sin \left(\omega t_{b}\right)\right)\right)
\end{gathered}
$$




$$
\begin{aligned}
\bar{V}_{c l}^{c}=\frac{1}{\pi} V\left(-\cos \left(\omega t_{c}\right)+\sqrt{3} \sin \left(\omega t_{c}\right)\right. \\
-\beta\left(\cos \left(\omega t_{c}\right)\right. \\
\left.\left.+\sqrt{3} \sin \left(\omega t_{c}\right)\right)\right)
\end{aligned}
$$

The variation of the DC component of each chainlink voltage with increasing unbalance factor is shown in

Figure 2

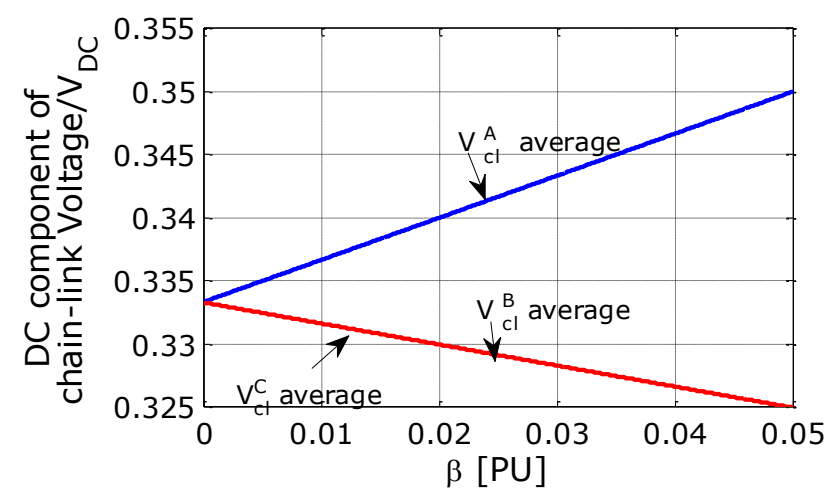

Figure 2: Variation of DC component of each chainlink with increasing unbalance factor

Considering $\beta$, the active power exchanged between each converter chain-link and the grid can be evaluated as

$$
\begin{aligned}
\bar{P}_{c l}=\frac{2 V I_{D C}}{\pi}( & +\beta) \\
& -\left(\frac{1+\beta}{2}\right) V I_{p} \cos \varphi \\
\bar{P}_{c l}^{b}=\frac{2 V I_{D C}}{\pi}( & \left.\cos \left(\omega t_{b}\right)-\sqrt{3} \sin \left(\omega t_{b}\right)\right) \\
& -\frac{\beta V I_{D C}}{\pi}\left(\cos \left(\omega t_{b}\right)\right. \\
& \left.+\sqrt{3} \sin \left(\omega t_{b}\right)\right) \\
& -\frac{V I_{p}}{2} \cos \varphi \\
& +\frac{\beta V I_{p}}{4}(\cos \varphi \\
& +\sqrt{3} \sin \varphi) \\
\overline{P^{c}} c l=\frac{2 V I_{D C}}{\pi}( & \left.\cos \left(\omega t_{c}\right)+\sqrt{3} \sin \left(\omega t_{c}\right)\right) \\
& -\frac{\beta V I_{D C}}{\pi}\left(\cos \left(\omega t_{c}\right)\right. \\
& \left.-\sqrt{3} \sin \left(\omega t_{b}\right)\right) \\
& -\frac{V I_{p}}{2} \cos \varphi \\
& +\frac{\beta V I_{p}}{4}(\cos \varphi \\
& -\sqrt{3} \sin \varphi)
\end{aligned}
$$

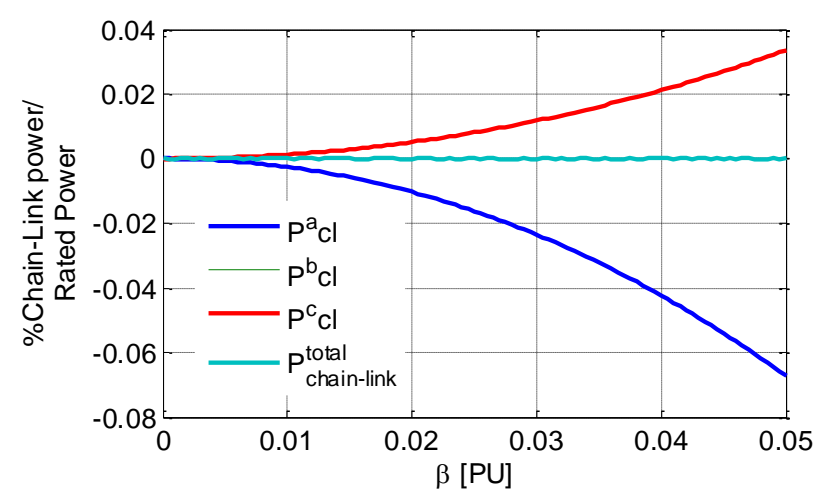

Figure 3: Change in active power in each converter chainlink for increasing voltage unbalance factor at unit $\mathrm{PF}$ operation for $20 \mathrm{MW} / 20 \mathrm{kV}$ (DC), $11 \mathrm{kV}$ (AC) system

From the net power exchange in Figure 3, it is clear that a remedial action is required for sustainable operation of the converter during grid voltage unbalance. It is worth indicating that though in this study, the converter voltage has been considered to be in phase with the system current. In practise, there will be a small phase shift between the converter voltage and the grid voltage (and therefore the system current during unity PF) due to the interface inductance; generally, the effect of this phase shift is taken care off by the general converter energy control. Therefore this effect has not been considered in the analysis.

\section{Proposed control concept for sustained operation during grid voltage unbalance}

It has been shown that during unbalanced grid voltage operation, the converter chain-links exchange unequal amounts of power with the grid requiring an appropriate remedial concept. In [7, 10, 13], the use of triplen harmonics are explored for modulation ratio control in the parallel hybrid modular multilevel converter (PH-M2L-VSC) allowing PQ control and DC link voltage ripple reduction. In these papers, the studies considered a balanced symmetrical grid with equal amount of triplen harmonic injected in each chain-link to allow fundamental frequency ac converter voltage control.

It shall be demonstrated in this paper that by injecting unequal amounts of triplen harmonics in the converter chain-link voltage demands proportional to the degree of unbalance, the operation of the converter can be sustained while maintaining power exchange with the grid. Consider the case where the chain-links are to synthesise the unbalance voltages imposed at the AC terminal as in (4), the voltage to be synthesised by the chain-links can be expressed as: 


$$
\begin{aligned}
V^{a}{ }_{c l}=V \mid(1+\beta) & \sin (\omega t) \\
& +\alpha_{a} \sin (3 \omega t) \mid \\
V^{b}{ }_{c l}=\mid V \sin (\omega t & \left.-\frac{2 \pi}{3}\right) \\
+ & \beta \sin \left(\omega t+\frac{2 \pi}{3}\right) \\
& +\alpha_{b} \sin (3 \omega t-\psi) \mid \\
V^{c}{ }_{c l}=\mid V \sin (\omega t & \left.+\frac{2 \pi}{3}\right) \\
& +\beta \sin \left(\omega t-\frac{2 \pi}{3}\right) \\
& +\alpha_{c} \sin (3 \omega t+\psi) \mid
\end{aligned}
$$

Where $\alpha_{a}, \alpha_{b}$, and $\alpha_{c}$, are the proportionate third harmonic voltages to be injected for sustainable operation during unbalance. $\Psi$ is the compensation term for the phase displacement on phases ' $b$ ' and ' $c$ ' during the zero voltage soft switching instant due to the unbalance.

From (16)(17)(18), the new DC component of the chain-link voltages can be obtained as:

$$
\begin{aligned}
& {\overline{V^{a}}}_{c l}=\frac{2}{\pi} V\left(1+\beta+\frac{\alpha_{a}}{3}\right) \\
& {\overline{V^{b}}}_{c l}=\frac{1}{\pi} V\left(-\cos \left(\omega t_{b}\right)+\sqrt{3} \sin \left(\omega t_{b}\right)\right. \\
& -\beta\left(\cos \left(\omega t_{b}\right)\right. \\
& \left.+\sqrt{3} \sin \left(\omega t_{b}\right)\right) \\
& \left.+\frac{2}{3} \alpha_{b} \cos \left(3 \omega t_{b}-\psi\right)\right) \\
& {\overline{V^{c}}}_{c l}=\frac{1}{\pi} V\left(-\cos \left(\omega t_{c}\right)-\sqrt{3} \sin \left(\omega t_{c}\right)\right. \\
& -\beta\left(\cos \left(\omega t_{c}\right)\right. \\
& \left.-\sqrt{3} \sin \left(\omega t_{c}\right)\right) \\
& \left.+\frac{2}{3} \alpha_{c} \cos \left(3 \omega t_{c}+\psi\right)\right)
\end{aligned}
$$

Under such conditions, the active power exchanged between each converter chain-link and the grid without reactive compensation can be expressed as:

$$
\begin{gathered}
\bar{P}_{c l}=\frac{2}{\pi} V I_{D C}\left(1+\beta+\frac{\alpha_{a}}{3}\right) \\
-\left(\frac{1+\beta}{2}\right) V I \\
\bar{P}_{c l}=\frac{1}{\pi} V I_{D C}(-a-\beta c \\
\left.+\frac{2}{3} \alpha_{b} \cos \left(3 \omega t_{b}-\psi\right)\right) \\
-\frac{V I}{4}(2-\beta)
\end{gathered}
$$

$$
\begin{aligned}
\bar{P}_{c l}^{c}=\frac{1}{\pi} V I_{D C}(- & b-\beta d \\
+ & \left.\frac{2}{3} \alpha_{c} \cos \left(3 \omega t_{c}+\psi\right)\right) \\
& -\frac{V I}{4}(2-\beta)
\end{aligned}
$$

Where a, b, c and d are described in (25).

$$
\begin{aligned}
& a=\cos \left(\omega t_{b}\right)-\sqrt{3} \sin \left(\omega t_{b}\right) \\
& b=\cos \left(\omega t_{c}\right)+\sqrt{3} \sin \left(\omega t_{c}\right) \\
& c=\cos \left(\omega t_{b}\right)+\sqrt{3} \sin \left(\omega t_{b}\right) \\
& d=\cos \left(\omega t_{c}\right)-\sqrt{3} \sin \left(\omega t_{c}\right)
\end{aligned}
$$

The net power exchanged between the converter chain-links and the grid (22), (23), (24) can be set to be equal and zero as required by using the appropriate values of $\alpha_{\mathrm{a}}, \alpha_{\mathrm{b}}$, and $\alpha_{\mathrm{c}}$.

The values for the required third harmonic voltage to be injected for varying amounts of unbalance can be obtained from (26)

$$
X=\Lambda^{-1} \Upsilon
$$

Where

$$
X=\left[\begin{array}{l}
\alpha_{a} \\
\alpha_{b} \\
\alpha_{c}
\end{array}\right]
$$

And

$$
\begin{gathered}
\bigwedge_{\frac{2}{3}}= \\
\left.\begin{array}{ccc}
(2-\beta) & -(1+\beta) \cos \left(3 \omega t_{b}-\psi\right) & -(1+\beta) \cos \left(\omega t_{c}+\psi\right) \\
(2-\beta) & -(4+\beta) \cos \left(3 \omega t_{b}-\psi\right) & (2-\beta) \cos \left(\omega t_{c}+\psi\right) \\
(2-\beta) & (2-\beta) \cos \left(3 \omega t_{b}-\psi\right)-(4+\beta) \cos \left(\omega t_{c}+\psi\right)
\end{array}\right] \\
Y=\left[\begin{array}{c}
A \\
B \\
C
\end{array}\right]
\end{gathered}
$$

In which the components of $\Upsilon$ are the unbalance factor dependant constants in the evaluation of (22), (23) and (24). 


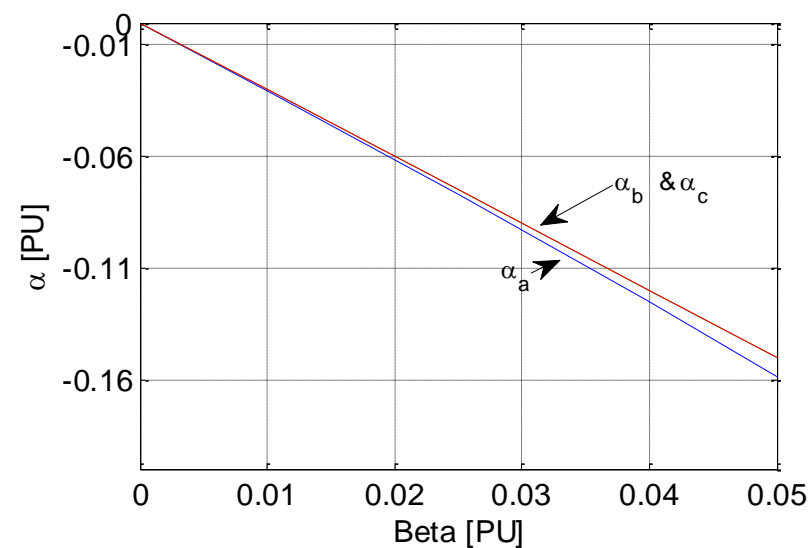

Figure 4: Amount of third harmonic voltage injected in each chain-link for increasing unbalance factor

Figure 4, shows the amount of third harmonic components required to sustain converter operation with significant unbalance factor (up to 5\%). The corresponding power exchanged between the grid and the converter chain-links when the converter operates with the proposed third harmonic injection control is shown Figure 5.

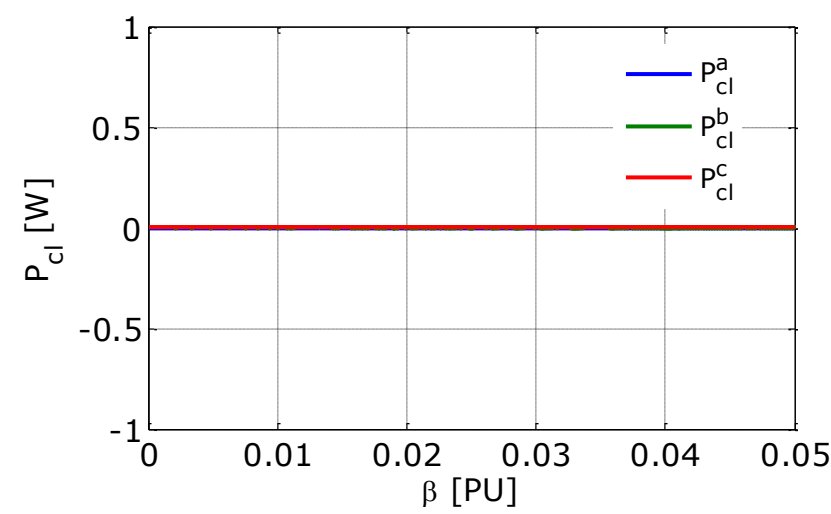

Figure 5: Active power exchanged between the converter chain-links and the grid with increasing voltage unbalance factor when the converter operates with the proposed voltage unbalance control

It is evident that the proposed third harmonic injection ensures equal and zero net power exchange between the chain-links of the converter and the grid. The asymmetric third harmonic voltage injection therefore ensures 'natural' power balance in each of the converter chain-links during unbalanced grid voltage operation.

\section{Modelling and Simulation}

The proposed concepts have been validated using simulation model of a $20 \mathrm{MW} 20 \mathrm{kV}$ (DC) converter connected to an $11 \mathrm{kV}$ grid. The unbalance in the voltage is represented by the presence of negative sequence voltage as shown Figure 6.
Techniques for extracting the reference frame components during unbalance [16] are used to obtain the unbalance factor $(\beta)$ in the grid and the proportion of third harmonic voltage required for sustainable operation is evaluated using the control concept discussed in the previous section. Table 1 lists the main parameters used in the simulation model.

The model is implemented using PLECS. The power flow control between the power converter and the grid, the power balance between the power converter and the DC circuit and the cell voltage control are achieved with the control schemes discussed in [7, 9, 10, 17].

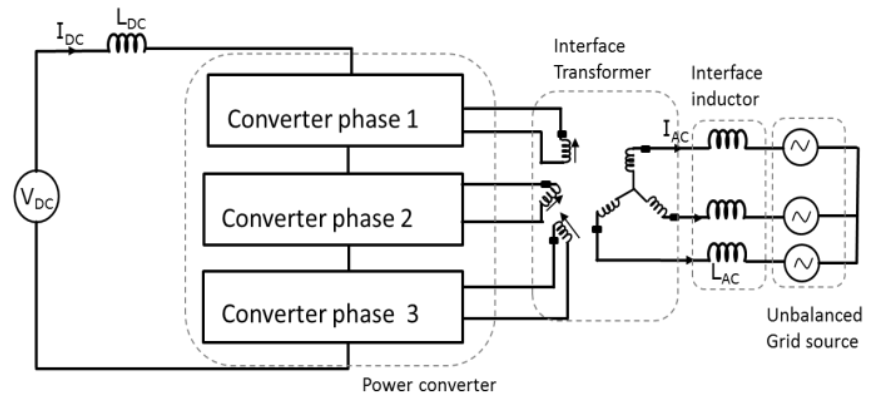

Figure 6: PH-M2L-VSC connected to an unbalanced AC network

Table 1: Simulation parameters

\begin{tabular}{||c||c||}
\hline \multicolumn{1}{|c|}{ Parameter } & Value \\
\hline \hline Supply voltage (L-L) & $11 \mathrm{kV}$ \\
\hline \hline DC bus voltage & $20 \mathrm{kV}$ \\
\hline \hline Unbalance factor & $1-5 \%$ \\
\hline \hline Cell capacitance & $4 \mathrm{mF}$ \\
\hline \hline DC Link inductance & $22.06 \mathrm{mH}$ \\
\hline AC side inductance & $2.3 \mathrm{mH}$ \\
\hline \hline $\begin{array}{c}\text { Nominal cell capacitor } \\
\text { voltage }\end{array}$ & $1.35 \mathrm{kV}$ \\
\hline
\end{tabular}

\section{Results and Discussion}

Results from the simulation model set up to validate the proposed control concepts are presented in Figure 7 to Figure 9. The line currents when the converter exchanges $20 \mathrm{MW}$ of power with the grid during 5\% unbalance operation are presented in Figure 7(a). It can be observed that the currents are of high quality with non-significant distortion.

Grid voltages during balanced and unbalanced operation are presented in Figure 6(b). It can be observed that the presented grid voltages are well balanced until the unbalance is introduced at $50 \mathrm{~ms}$ from start of the simulation. The 
corresponding voltage synthesised by the converter during balanced operation (before $50 \mathrm{~ms}$ ) and unbalanced operation (after 50ms) are shown in Figure 7(c).

The cell voltages of the chain-links are presented in Figure 8. It is shown that before $50 \mathrm{~ms}$ when the converter exports 20MW with the balanced grid, the voltages on all the capacitors in the three chain-links pulsate about same nominal value of $1350 \mathrm{~V}$.
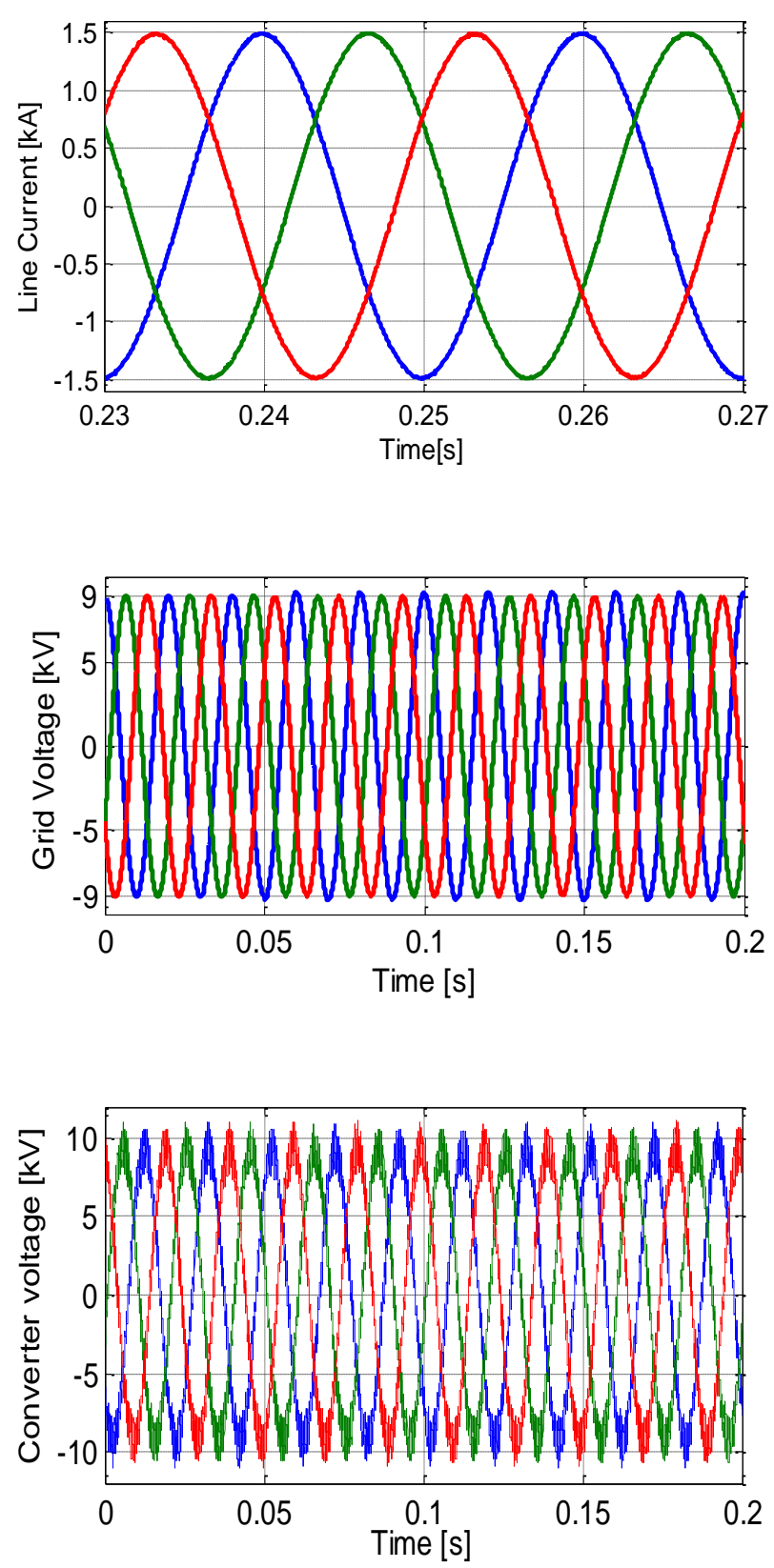

Figure 7: Converter waveforms (a) Line currents, (b) Grid voltages with $5 \%$ unbalance factor, and (c) Converter terminal voltages

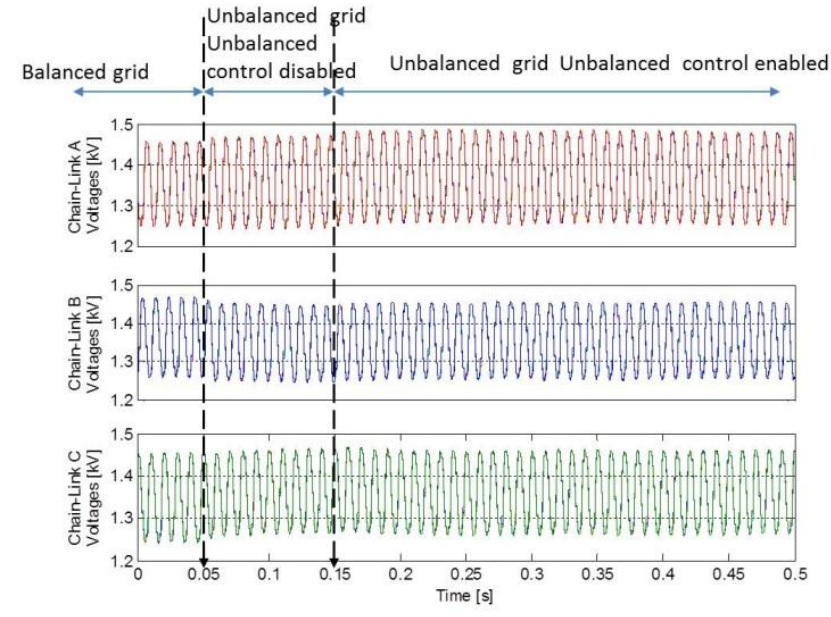

Figure 8: Converter cell capacitor voltages

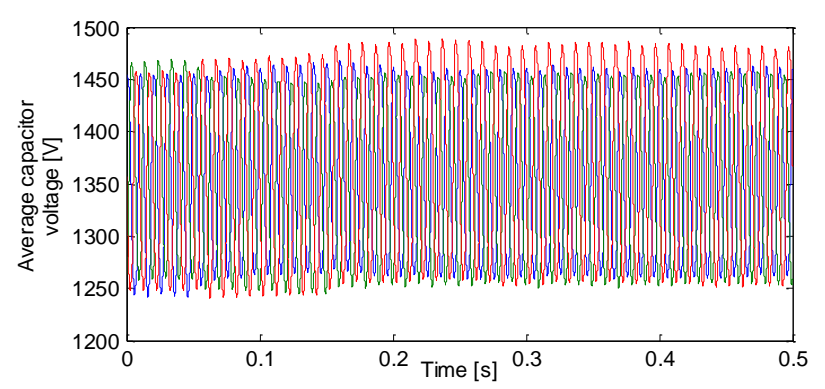

Figure 9: Average capacitor voltage for each converter chainlink

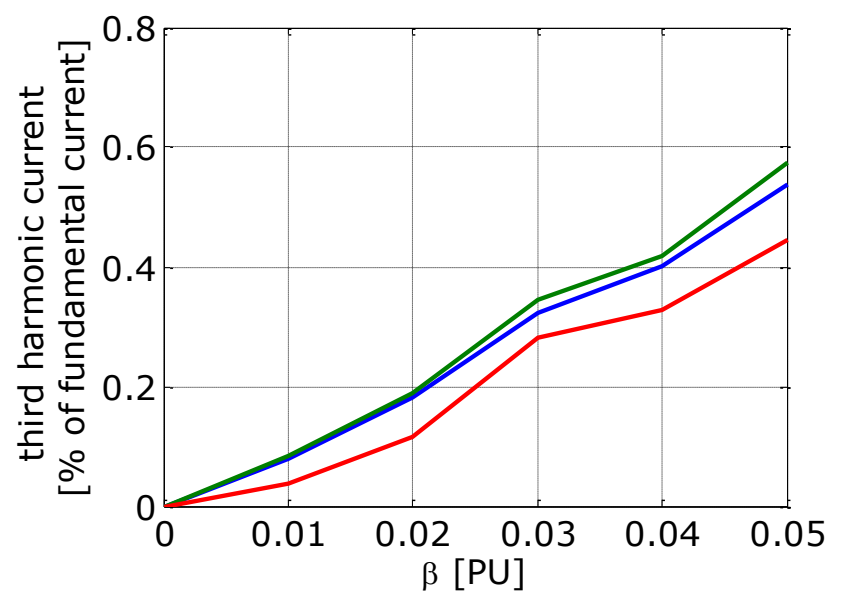

Figure 10: Effect of unbalance control concept on grid current

However, when the unbalance is introduced at $50 \mathrm{~ms}$, it can be observed that the voltages in the chain-links begin to drift apart. When the proposed unbalance control is applied at $150 \mathrm{~ms}$, equilibrium is restored soon after and all the cell voltages pulsate about same mean as shown in Figure 9. The effect of the proposed unbalance control concept on the grid currents is shown in Figure 10. It is shown that for unbalances up to $5 \%$ the effect of the residual third harmonic current in the grid due to the control concept is less than $0.6 \%$. 


\section{Conclusion}

A novel method for the control of a parallel hybrid modular multilevel converter during voltage unbalance is proposed. It is shown that sustainable operation of the converter can be achieved during unbalance by injecting a proportionate amount of third harmonic (maximum of $16 \%$ third harmonic for $5 \%$ unbalance factor) into the chain-links. The proposed method has been validated through mathematical analysis and simulation modelling using PLECS. Results from the simulation model have been presented to support the performance of the converter during grid voltage unbalance.

\section{Acknowledgement}

The authors gratefully acknowledge the support of Alstom Grid (formerly Areva T\&D) in undertaking this research.

\section{References}

[1] N. Flourentzou, V. G. Agelidis, and G. D. Demetriades, "VSC-Based HVDC Power Transmission Systems: An Overview," Power Electronics, IEEE Transactions on, vol. 24, pp. 592$602,2009$.

[2] S. Allebrod, R. Hamerski, and R. Marquardt, "New transformerless, scalable Modular Multilevel Converters for HVDC-transmission," in Power Electronics Specialists Conference, 2008. PESC 2008. IEEE, 2008, pp. 174-179.

[3] N. Ahmed, A. Haider, D. Van Hertem, Z. Lidong, and H. P. Nee, "Prospects and challenges of future HVDC SuperGrids with modular multilevel converters," in Power Electronics and Applications (EPE 2011), Proceedings of the 2011-14th European Conference on, 2011, pp. 1-10.

[4] B. Jacobsen, Karlsson, P., Asplund, G., Harnefors,L., Jonsson,T., $\quad$ "VSC-HVDC Transmission with cascaded Two-level Converters," in CIGRE, 2010.

[5] D. R. Trainer, Davidson, C. C., Oates, C. D. M. Macleod, N. M., \& Critchley, D. R. , "A New Hybrid Voltage-Sourced Converter for HVDC Power Transmission," in Cigre 2010.

[6] M. M. C. Merlin, T. C. Green, P. D. Mitcheson, D. R. Trainer, R. Critchley, W. Crookes, et al., "The Alternate Arm Converter: A New Hybrid Multilevel Converter With DC-Fault Blocking Capability," Power Delivery, IEEE Transactions on, vol. 29, pp. 310-317, 2014.
R. Feldman, M. Tomasini, E. Amankwah, J. C. Clare, P. W. Wheeler, D. R. Trainer, et al., "A Hybrid Modular Multilevel Voltage Source Converter for HVDC Power Transmission," Industry Applications, IEEE Transactions on, vol. 49, pp. 1577-1588, 2013.

[8] G. P. Adam, Finney, S. J., Williams, B. W.,Trainer, D. R.,Oates, C. D. M.,Critchley, D. R., "Network fault tolerant voltage-source-converters for highvoltage applications," in $A C$ and $D C$ Power Transmission, 2010. ACDC. 9th IET International Conference on, 2010, pp. 1-5.

[9] E. K. Amankwah, J. C. Clare, P. W. Wheeler, and A. J. Watson, "Cell capacitor voltage control in a parallel hybrid modular multilevel voltage source converter for HVDC applications," in Power Electronics, Machines and Drives (PEMD 2012), 6th IET International Conference on, 2012, pp. 1-6.

[10] E. Amankwah, A. Watson, R. Feldman, J. Clare, and P. Wheeler, "Experimental validation of a parallel hybrid modular multilevel voltage source converter for HVDC transmission," in Applied Power Electronics Conference and Exposition (APEC), 2013 Twenty-Eighth Annual IEEE, 2013, pp. 16071614.

[11] R. Feldman, M. Tomasini, J. C. Clare, P. Wheeler, D. R. Trainer, and R. S. Whitehouse, "A low loss modular multilevel voltage source converter for HVDC power transmission and reactive power compensation," in AC and DC Power Transmission, 2010. ACDC. 9th IET International Conference on, 2010, pp. $1-5$.

[12] R. Feldman, Tomasini, M., Clare, J C., Wheeler, P. ,Trainer, D R. ,Whitehouse, R S.,, "A hybrid voltage source converter arrangement for HVDC power transmission and reactive power compensation," presented at the Power Electronics, Machines and Drives (PEMD 2010), 5th IET International Conference on, 2010.

M. Tomasini, R. Feldman, J. C. Clare, P. Wheeler, D. R. Trainer, and R. S. Whitehouse, "DC-Link voltage ripple minimization in a modular multilevel voltage source converter for HVDC power transmission," in Power Electronics and Applications (EPE 2011), Proceedings of the 201114th European Conference on, 2011, pp. 1-10.

[14] C. L. Fortescue, "Polyphase Power Representation by Means of Symmetrical Coordinates," American Institute of Electrical Engineers, Transactions of the, vol. XXXIX, pp. 1481-1484, 1920. 
[15] C. L. Fortescue, "Method of symmetrical coordinates applied to the solution of polyphase networks," American Institute of Electrical Engineers, Proceedings of the, vol. 37, pp. 629-716, 1918.

[16] P. Rodriguez, J. Pou, J. Bergas, J. I. Candela, R. P. Burgos, and D. Boroyevich, "Decoupled Double Synchronous Reference Frame PLL for Power Converters Control," Power Electronics, IEEE Transactions on, vol. 22, pp. 584-592, 2007.

[17] E. K. Amankwah, J. C. Clare, P. W. Wheeler, and A. J. Watson, "Multi carrier PWM of the modular multilevel VSC for medium voltage applications," in Applied Power Electronics Conference and Exposition (APEC), 2012 Twenty-Seventh Annual IEEE, 2012, pp. 2398-2406. 